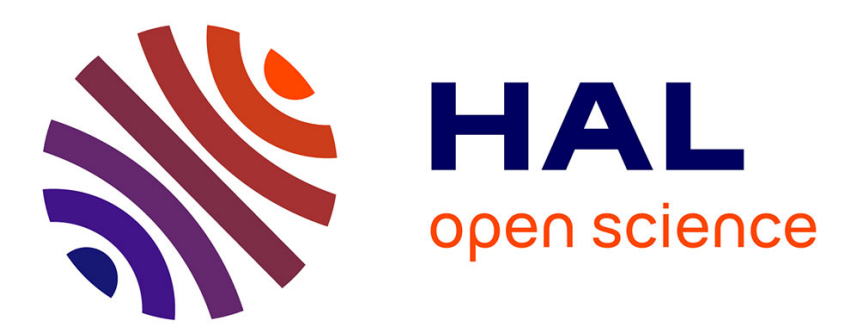

\title{
Modelling an abrasive wear experiment by the boundary element method
}

\author{
I. Serre, Marc Bonnet, R. M. Pradeilles-Duval
}

\section{To cite this version:}

I. Serre, Marc Bonnet, R. M. Pradeilles-Duval. Modelling an abrasive wear experiment by the boundary element method. Comptes Rendus de l'Academie des Sciences Serie II, 2001, 329, pp.803-808. 10.1016/S1620-7742(01)01402-7 . hal-00092386

\section{HAL Id: hal-00092386 \\ https://hal.science/hal-00092386}

Submitted on 11 Aug 2008

HAL is a multi-disciplinary open access archive for the deposit and dissemination of scientific research documents, whether they are published or not. The documents may come from teaching and research institutions in France or abroad, or from public or private research centers.
L'archive ouverte pluridisciplinaire HAL, est destinée au dépôt et à la diffusion de documents scientifiques de niveau recherche, publiés ou non, émanant des établissements d'enseignement et de recherche français ou étrangers, des laboratoires publics ou privés. 


\title{
Modelling an abrasive wear experiment by the boundary element method
}

\author{
Ingrid Serre $^{\text {a,b }}$, Marc Bonnet ${ }^{\text {b }}$, Rachel-Marie Pradeilles-Duval ${ }^{\text {b }}$ \\ a DGA/DCE, Centre technique d'Arcueil, 94114 Arcueil, France. \\ b Laboratoire de mécanique des solides (CNRS UMR 7649), Ecole polytechnique, 91128 Palaiseau cedex, France \\ E-mail: bonnet@lms.polytechnique.fr,rachel@lms.polytechnique.fr
}

(Reçu le $1^{\text {er }}$ juin 2001, accepté le 3 septembre 2001)

\begin{abstract}
This note presents a computational technique for simulating friction-induced wear in a tribology experiment on a plan / plan, ring-on-disc contact configuration. The boundary element method results in modest computing times and facilitates the mesh modifications used for tracking the wear profile evolution. A typical wear simulation result is presented and discussed. (C) 2001 Académie des sciences/Éditions scientifiques et médicales Elsevier SAS abrasive wear / modelling / boundary elements
\end{abstract}

Simulation d'une expérience d'usure sous frottement par éléments de frontière

Résumé. Cette Note présente, pour une configuration de contact plan / plan de type anneau sur disque étudiée lors d'essais de tribologie, une méthode de simulation de l'évolution du profil d'usure abrasive fondée sur les éléments de frontière, qui permet des temps de calcul raisonnables et facilite le suivi du profil. Une simulation typique est présentée et commentée. (C) 2001 Académie des sciences/Éditions scientifiques et médicales Elsevier SAS

usure abrasive / simulation / éléments de frontière

\section{Version française abrégée}

L'usure résulte de frottements, parfois couplés avec de la corrosion. Sa prise en compte est importante pour les calculs de structure prédictifs. Cette Note concerne la simulation numérique de l'usure d'origine mécanique sur un système formé de deux anneaux coaxiaux en milieu marin (figure 1), conçu comme idéalisation d'un composant d'étanchéité maritime, qui a été l'objet d'une étude expérimentale de tribocorrosion [5]. L'objectif visé à long terme est l'identification par approche inverse de la loi d'usure, pour laquelle la méthode directe présentée ici est un composant essentiel.

L'algorithme développé est conçu «sur mesure »pour les frottements de type anneau sur anneau, et exploite notamment la symétrie de révolution (coordonnées cylindriques $O, r, \theta, z$ ) et l'indépendance en $\theta$ des composantes de toutes les grandeurs mécaniques (dans la base cylindrique). Il repose par ailleurs sur un ensemble d'hypothèses : régime quasi-statique et comportement élastique linéaire des deux matériaux antagonistes (équations de champ (11) ; glissement total, frottement de Coulomb et nullité de la projection

\section{Note présentée par Huy Duong BUI}

S1620-7742(01)01402-7/FLA

(c) 2001 Académie des sciences/Éditions scientifiques et médicales Elsevier SAS. Tous droits réservés. 


\section{Serre, M. Bonnet, R.M. Pradeilles-Duval}

radiale de la contrainte tangentielle de contact (conditions (3) sur la surface de contact $S_{c}$ ); loi d'usure locale (4) donnant la vitesse d'usure locale $f_{w}(\boldsymbol{x}, t)$, normale à $S_{c}$, comme fonction de la pression de contact locale $p(\boldsymbol{x}, t)$ et de la vitesse de frottement $V(\boldsymbol{x})$.

L'algorithme procède par intégration discrète en temps (pas de temps $\Delta t$ ). L'évolution de l'usure étant très lente, chaque incrément de temps (passage $t_{n} \rightarrow t_{n+1}$, avec $t_{k}=k \Delta t$ ) consiste en (i) trouver la solution stationnaire en pression de contact à profil fixé, puis (ii) une actualisation du profil au moyen de la loi d'usure discrétisée sous forme explicite (6), bien qu'en toute rigueur les deux effets soient couplés. La résolution étant pilotée par les variables mécaniques sur $S_{c}$, s'appuie sur une discrétisation par éléments de frontière de l'équation intégrale (5) reliant toute paire $(\boldsymbol{u}, \boldsymbol{p})$ de vecteurs déplacement et contrainte compatibles avec (1). Après incorporation de conditions aux limites (2) et de contact (3), un calcul itératif permet de trouver (entre autres) la pression de contact $p\left(\boldsymbol{x}, t_{n+1}\right)$ sur $S_{c}$ pour les profils $f^{1,2}\left(\boldsymbol{x}, t_{n}\right)$, ces derniers étant ensuite actualisés (phase (ii)). L'utilisation des éléments de frontière simplifie par ailleurs fortement l'actualisation du maillage correspondant à l'évolution discrète du profil d'usure.

Dans le but de montrer la faisabilité de ce type de simulation, on traite la configuration de la figure 2, les anneaux 1 et 2 occupant les régions $\omega_{1}=\{20 \mathrm{~mm} \leq r \leq 40 \mathrm{~mm}, 0 \leq z \leq 20 \mathrm{~mm}\}$ et $\omega_{2}=\{28,5 \mathrm{~mm} \leq$ $r \leq 31,5 \mathrm{~mm}, 20 \mathrm{~mm} \leq z \leq 40 \mathrm{~mm}\}$. Les paramètres de comportement utilisés sont $E_{1}=10 \mathrm{GPa}$ et $E_{2}=100 \mathrm{GPa}$ (modules d'Young), $\nu_{1}=\nu_{2}=0.3$ (coefficient de Poisson), $\mu=0.1$ (coefficient de frottement), $k_{1}=10^{-7} \mathrm{MPa}^{-1}$ et $p_{1}^{0}=0$ ou $40 \mathrm{MPa}$; seul l'anneau 1 est supposé s'user $\left(k_{2}=0\right)$. La base de l'anneau 1 est bloquée en déplacement, alors qu'un déplacement vertical uniforme est appliqué (dans le repère tournant) en face supérieure de l'anneau 2. La figure 2 montre l'usure calculée (ici, l'évolution de la surface de contact sur l'anneau 1). Celle-ci s'initie sous les bords de l'anneau 2, où apparaissent des pics de pression de contact, et reste maximale aux bords après un grand nombre d'incréments; cette constatation est corroborée par les résultats d'expériences en tribocorrosion [5, 6]. Les évolutions calculées de l'enfoncement dépendent substantiellement des paramètres de la loi d'usure (voir figure 2, comparaison pour $p_{1}^{0}=0$ ou $40 \mathrm{MPa}$ ), ce qui suggère que l'identification de lois d'usure à partir de mesures d'évolution de l'enfoncement (disponibles par exemple dans les expériences menées dans [5]) est réalisable.

En conclusion, la simulation d'usure sur des systèmes spécifiques tels que celui présenté ici ne demande que des ressources informatiques modestes; on s'attend donc à ce qu'il en soit de même pour le problème inverse d'identification de lois d'usure. La méthode des éléments de frontière apparaît comme bien adaptée, du moins sous l'hypothèse de comportements linéaires hors de la zone de contact, et ce notamment grâce à la facilité d'actualisation de maillage. De plus, la méthode présentée ici n'est pas restreinte aux lois d'usure de forme (凹), et pourrait être étendue aux matériaux revêtus, selon une approche calquée sur [3].

\section{Introduction}

Wear occurs due to friction, possibly coupled with corrosion. Due to its adverse effect on structural integrity, it is important to take such phenomena into account for design or lifetime prediction purposes.

This work stems from the experimental study of coupled mechanical / electrochemical wear [5]. The system under study, conceived as the idealization of an industrial component used at sea for watertightness purposes, consisted of two coaxial rings on top of one another and in contact, with the lower ring kept fixed and the upper ring rotating about its axis of revolution (figure 1). The two rings were immersed in seawater, so that wear occured due to both mechanical and electrochemical effects.

To extrapolate results from such experiments to more complex structures made with the same antagonist materials, and in particular to be able to perform meaningful predictive calculations on such structures, requires information about the frictional and wear behaviour of the two antagonist materials. Such information is usually formulated as a friction law (e.g. the Coulomb law) and a wear law, which relates the local rate of wear to the local relative velocity of the antagonists and contact stresses. Neither the functional form nor the parameters defining a wear law are well known in advance. It is thus desirable to infer the wear law 
characteristics from wear experiments, by formulating and solving an inverse problem. This in turn rests upon the possibility of computing the experimental data that would be recorded for a known wear law.

As a first step towards this goal, an algorithm has been developed to compute the mechanical wear for a given wear law; this is the subject of the present communication. The algorithm is tailored for the specific geometrical characteristics of the experiment, i.e. for ring-on-ring or ring-on-disc configurations where the wear is caused by the rotation of the upper ring on the lower one. Our approach is oriented towards predicting the macroscopic behaviour of the mechanical system. Accordingly, the antagonist materials are assumed to have isotropic and homogeneous constitutive properties. In fact, since the experimentally recorded contact pressures were usually less than $10 \mathrm{MPa}$, it is legitimate to assume linearly elastic constitutive properties for both antagonists. Our approach leaves out both the third body and the motion of wear debris in the contact zone. The electrochemical effects present in the experiments can be accounted for only to a limited extent, through the values of the friction coefficient and wear law parameters.

\section{Basic hypotheses and governing equations}

Let $(O, r, \theta, z)$ denote a cylindrical coordinate system. Both the lower disc (or ring) and the upper ring, having rotational symmetry about $O z$, occupy domains $\Omega^{1}$ and $\Omega^{2}$ that are generated by the rotation of domains $\omega_{1}$ and $\omega_{2}$ about $O z$. In addition, the components relative to the frame $\left(\boldsymbol{e}_{r}, \boldsymbol{e}_{\theta}, \boldsymbol{e}_{z}\right)$ of all mechanical variables are functions of $(r, z)$ only; the same symmetry assumption is made for the wear profile. Therefore, the underlying mathematical problem to be (numerically) solved is essentially two-dimenstional (in the $(r, z)$-plane), although not axisymmetric due to the presence of nonzero (but $\theta$-independent) orthoradial components. In particular, having assumed elastic constitutive behaviour for both antagonist materials and neglecting inertia effects, the displacements $\boldsymbol{u}^{J}$, strains $\boldsymbol{\varepsilon}^{J}$, stresses $\boldsymbol{\sigma}^{J}$ in each domain $\omega_{J}(J=1,2)$ are governed by the field equations of elastic equilibrium:

$$
\operatorname{div}_{2} \boldsymbol{\sigma}^{J}=0 \quad \varepsilon^{J}=\frac{1}{2}\left(\nabla_{2}+\nabla_{2}^{T}\right) \boldsymbol{u}^{J} \quad \boldsymbol{\sigma}^{J}=\boldsymbol{C}^{J}: \varepsilon^{J} \quad\left((r, z) \in \omega_{J}\right)
$$

where the differential operators $\nabla_{2}$ and $\operatorname{div}_{2}$ are obtained by expressing the usual (three-dimensional) gradient and divergence in cylindrical coordinates and removing all partial derivatives w.r.t. $\theta$. Besides, the boundary conditions away from the contact area are assumed of the form:

$$
\boldsymbol{\sigma}^{J} \cdot \boldsymbol{n}=\overline{\boldsymbol{p}}^{J} \quad\left(\text { on } \partial \omega_{J}^{p}\right) \quad \boldsymbol{u}^{J}=\overline{\boldsymbol{u}}^{J} \quad\left(\text { on } \partial \omega_{J}^{u}\right)
$$

having introduced partitions $\partial \omega^{J}=\partial \omega_{J}^{p} \cup \partial \omega_{J}^{u} \cup S_{c}$, where $S_{c}$ is the contact area and $\partial \omega_{J}^{p}$ and $\partial \omega_{J}^{u}$ are the portions of $\partial \omega_{J}$ supporting prescribed tractions and displacements, respectively. Note that for $\omega_{2}$ (i.e. the rotating ring) equations (11) and (2) are formulated in the rotating cylindrical frame. As a further simplification, the initial transient regime is not modelled. This choice is supported by finite element (FE) simulations of the initial transient regime [5] showing that a steady-state regime is reached very early. Thus, the entire contact area is assumed to be in slip mode, with the slip direction being orthoradial. Besides, the radial component of the contact stress is neglected (i.e. $\sigma_{r z}=0$ on $S_{c}$ ), an assumption also backed by the same FE simulations. The contact profile $f$, the stresses and the displacements on the contact area are found to be subject to the conditions (in which $\mu$ is the friction coefficient, assuming a Coulomb friction law):

$$
\begin{array}{ccc}
\sigma_{z z}^{2}=\sigma_{z z}^{1} \quad \sigma_{z r}^{2}=\sigma_{z r}^{1}=0 & \sigma_{z \theta}^{2}=\sigma_{z \theta}^{1} & \left|\sigma_{z \theta}^{2}\right|=\mu\left|\sigma_{z z}^{2}\right| \\
u_{z}^{2}-u_{z}^{1} \geq f^{1}-f^{2} & \sigma_{z z} \leq 0 & \sigma_{z z}\left(u_{z}^{2}+f^{2}-u_{z}^{1}-f^{1}\right)=0
\end{array}
$$

For each antagonist material, the local rate of wear $f_{w}(\boldsymbol{x}, t)$ at $\boldsymbol{x} \in S_{c}$, at time $t$ and in the direction normal to $S_{c}$ is related to the contact pressure $p(\boldsymbol{x}, t)$ through a wear law of the following form, chosen so as to express that the local rate of wear is proportional (with a factor $k_{J}$ ) to the local dissipated power density:

$$
f_{w}^{J}(\boldsymbol{x}, t)=k_{J} \mu \operatorname{Max}\left\{0, p(\boldsymbol{x}, t)-p_{J}^{0}\right\} V(\boldsymbol{x}) \quad\left(\boldsymbol{x} \in S_{c}, J=1,2\right)
$$




\section{Serre, M. Bonnet, R.M. Pradeilles-Duval}

where $V(\boldsymbol{x})$ is the relative velocity at $\boldsymbol{x}$ between the antagonists and $p_{J}^{0}$ is a contact pressure threshold below which no wear occurs at $\boldsymbol{x}$. The parameters $k^{J}, p_{J}^{0}$ and $\mu$ may depend on the mechanical and electrochemical variables. Each antagonist shape is thus a function of time, i.e. $\omega_{J} \equiv \omega_{J}(t)$.

Since the rate of wear depends on the contact pressure through (\#) and the contact pressure in turn depends on the contact profile, which of course evolves due to wear, the contact and wear phenomena are $a$ priori coupled (this point is illustrated by Lederer [4] for wear created by sliding, in a plane-strain situation).

\section{Solution algorithm}

The critical equations (which also are the only non-linear ones) are the wear law (4) and the contact conditions (3), both supported by the contact surface $S_{c}$. The field variables inside the domains are needed only insofar as to ensure satisfaction of the field equations (1). This consideration led us to develop a solution procedure based on the boundary element method (BEM), see [2] for a recent exposition, in order to solve the problem in a boundary-only fashion. As an added advantage, it is much easier to monitor the evolution of $S_{c}(t)$ with the BEM than with a domain-based technique such as the finite element method.

The BEM is based on the fact that the boundary trace $\left(\boldsymbol{u}^{J}, \boldsymbol{p}^{J}=\boldsymbol{\sigma}^{J}\left(\boldsymbol{u}^{J}\right) . \boldsymbol{n}^{J}\right)$ on $\partial \omega_{J}(t)$ of any solution to the field equations (11) in each antagonist $\omega_{J}(t)$ are related through the boundary integral equation:

$$
\int_{\partial \omega_{J}(t)} r_{1}\left\{T_{i}^{k}(\boldsymbol{x}, \boldsymbol{y})\left[u_{i}^{J}(\boldsymbol{y}, t)-u_{i}^{J \star}(\boldsymbol{y})\right]-U_{i}^{k}(\boldsymbol{x}, \boldsymbol{y})\left[p_{i}^{J}(\boldsymbol{y}, t)-p_{i}^{J \star}(\boldsymbol{y})\right]\right\} \mathrm{d} s_{y}=0
$$

where $\boldsymbol{U}^{k}(\boldsymbol{x}, \boldsymbol{y})$ and $\boldsymbol{T}^{k}(\boldsymbol{x}, \boldsymbol{y})$ denote respectively the displacement and traction vectors associated with the (rotationally symmetric) elastostatic fundamental solution, i.e. the response at $\boldsymbol{y}=\left(r_{1}, \theta=0, z_{1}\right) \in \omega$ of an infinite elastic body to a distribution over the horizontal circle generated by rotation of the point $\boldsymbol{x}=(r, \theta=0, z) \in \omega$ about the symmetry axis of unit point forces applied along direction $\boldsymbol{e}_{k}(k \in\{r, \theta, z\})$. This fundamental solution, which can be obtained by an angular integration of the Kelvin three-dimensional fundamental solution [ [5], is singular $\left(\boldsymbol{U}^{k}=O(\log |\boldsymbol{y}-\boldsymbol{x}|)\right.$ and $\left.\boldsymbol{T}^{k}=O\left(|\boldsymbol{y}-\boldsymbol{x}|^{-1}\right)\right)$. Known (rigid-body or constant-strain) solutions $\left(\boldsymbol{u}^{J \star}(\boldsymbol{y}), \boldsymbol{p}^{J \star}(\boldsymbol{y})\right)$ of the field equations, chosen such that $\boldsymbol{u}^{J \star}(\boldsymbol{x})=\boldsymbol{u}^{J}(\boldsymbol{x}, t)$, are used in order to write equation (5) in regularized form [2].

To formulate properly the wear evolution problem in rate form, one would have to apply the domain derivative technique to the integral equation (5) [1], in order to obtain a linear relation between $f_{w}(\boldsymbol{x}, t)$ and the rates $(\dot{\boldsymbol{u}}, \dot{\boldsymbol{p}})$, supplemented with the boundary conditions (2), (3) in rate form and the wear law (4); contact and wear are coupled in the resulting rate problem. In fact, a very slow evolution of the contact profile $f^{J}$ induced by wear is expected. Uncoupling the numerical treatment of contact and wear is thus a legitimate approximation, adopted here, whereby in particular the domain differentiation of (5) is avoided.

In practice, a time-stepping approach is adopted, with a time step $\Delta t$. The total number of time steps (for a given $\Delta t$ ) is to be determined from either the total duration of the experiment or the cumulated slip distance. Besides, a space discretization is also introduced, whereby $\partial \omega_{J}$ are divided into piecewise linear boundary elements, and piecewise constant and (continuous) piecewise linear discretizations are used for the tractions and displacements, respectively. For solving each time increment, i.e. for finding the (new) mechanical fields and contact profile at time $t_{n+1}=(n+1) \Delta t$ from the (current) known ones at time $t_{n}=n \Delta t$, two operations are performed in succession:

(i) The new mechanical fields are found by solving the contact problem for the current profile $f^{J}\left(\boldsymbol{x}, t_{n}\right)$. In order to do so, the (BEM-discretized) integral equation (5) and the boundary and contact conditions (2) and (3) are all considered for the domains $\omega_{J}\left(t_{n}\right)$ but the variables $\{\boldsymbol{u}, \boldsymbol{p}\}\left(\cdot, t_{n+1}\right)$. Solving the resulting nonlinear problem for the remaining boundary unknowns after incorporation of the boundary conditions into (5) yields the new distributions $\{\boldsymbol{u}, \boldsymbol{p}\}\left(\cdot, t_{n+1}\right)$ over the contact area $S_{c}$.

(ii) the new contact profile is obtained by invoking the wear law (4) in finite-difference form:

$$
\begin{array}{ll}
f^{2}\left(\boldsymbol{x}, t_{n+1}\right)=f^{2}\left(\boldsymbol{x}, t_{n}\right)+f_{w}^{2}\left(\boldsymbol{x}, t_{n+1}\right) \Delta t & \text { on } S_{c} \\
f^{1}\left(\boldsymbol{x}, t_{n+1}\right)=f^{1}\left(\boldsymbol{x}, t_{n}\right)-f_{w}^{1}\left(\boldsymbol{x}, t_{n+1}\right) \Delta t & \text { on } S_{c}
\end{array}
$$




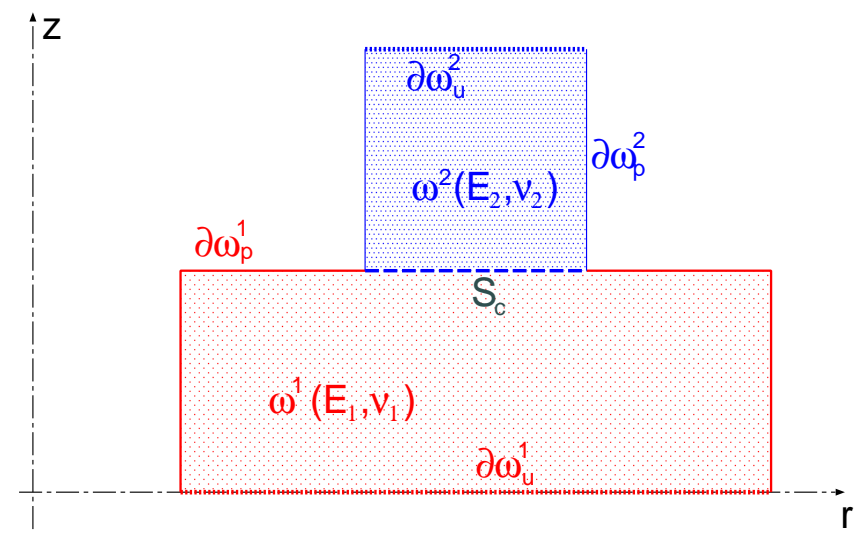

Figure 1: Numerical example of wear simulation: geometrical configuration (in the $(r, z)$-plane). Exemple numérique de simulation d'usure: configuration géométrique (dans le plan $(r, z)$ ).

where the local rates of wear $f_{w}^{1}, f_{w}^{2}$ are assumed to take positive values along the directions $-\boldsymbol{e}_{z}$ and $e_{z}$, respectively.

\section{Numerical example of wear simulation}

This example aims at demonstrating the feasibility of wear simulation using the approach described in the previous section and subject to the hypotheses stated therein.

In the configuration studied, rings 1 and 2 are defined by $\omega_{1}=\{20 \mathrm{~mm} \leq r \leq 40 \mathrm{~mm}, 0 \leq z \leq 20 \mathrm{~mm}\}$ and $\omega_{2}=\{28,5 \mathrm{~mm} \leq r \leq 31,5 \mathrm{~mm}, 20 \mathrm{~mm} \leq z \leq 40 \mathrm{~mm}\}$. Zero displacements are prescribed on the base of ring 1, while a uniform vertical displacement (relative to the rotating frame) is imposed on the top surface of ring 2. Outside the contact area, the remaining portions of $\omega_{1}$ and $\omega_{2}$ are assumed traction-free. The constitutive parameters used are $E_{1}=10 \mathrm{GPa}$ and $E_{2}=100 \mathrm{GPa}$ (Young moduli), $\nu_{1}=\nu_{2}=0.3$ (Poisson ratios), $\mu=0.1$ (Coulomb friction coefficient), $k_{1}=10^{-7} \mathrm{MPa}^{-1}$ and $p_{1}^{0}=0$ or $40 \mathrm{MPa}$ (wear law parameters for ring 1). Besides, wear is assumed to occur in ring 1 only, i.e. $k_{2}=0$.

The computed wear (here, the evolution of the contact surface of ring 1) is shown on figure 2. Due to the wear law form (4) being used, the computed wear is initiated under the two edges of ring 2 , where the contact pressure is, as expected, highest; the same feature is also found in results of ring-on-disc tribocorrosion experiments [5, 6]. The same qualitative observation was made with the corners of ring 2 cut into chamfers. Results for later time steps ( $n=150$ or 200 ) exhibit slightly oscillatory wear profile shapes, which are likely to be caused by some kind of numerical instability in the time-stepping scheme.

A comparison of computed penetration depth evolutions for $p_{1}^{0}=0$ or $40 \mathrm{MPa}$ (figure 2) shows that the wear evolution is substantially influenced by the values of the wear law parameters. Thus, an identification of these parameters from measurements of wear evolution, which are available e.g. in the experimental setup developed in [5], can reasonably be expected to be feasible.

\section{Conclusions}

The preliminary results presented here demonstrate the feasibility of such wear simulation. Upon optimization and careful parametric studies of the numerical algorithm, which are yet to be done, the simulation of wear for specialized setups like the one studied here require only very modest computing resources. This is expected to make the inverse problem of wear law identification manageable with small-scale computers.

Irrespective of specific geometric arrangements such as the one considered in this paper, the BEM appears to be an adequate tool for the simulation of wear, at least when, as here, linear constitutive behaviour of the 


\section{Serre, M. Bonnet, R.M. Pradeilles-Duval}
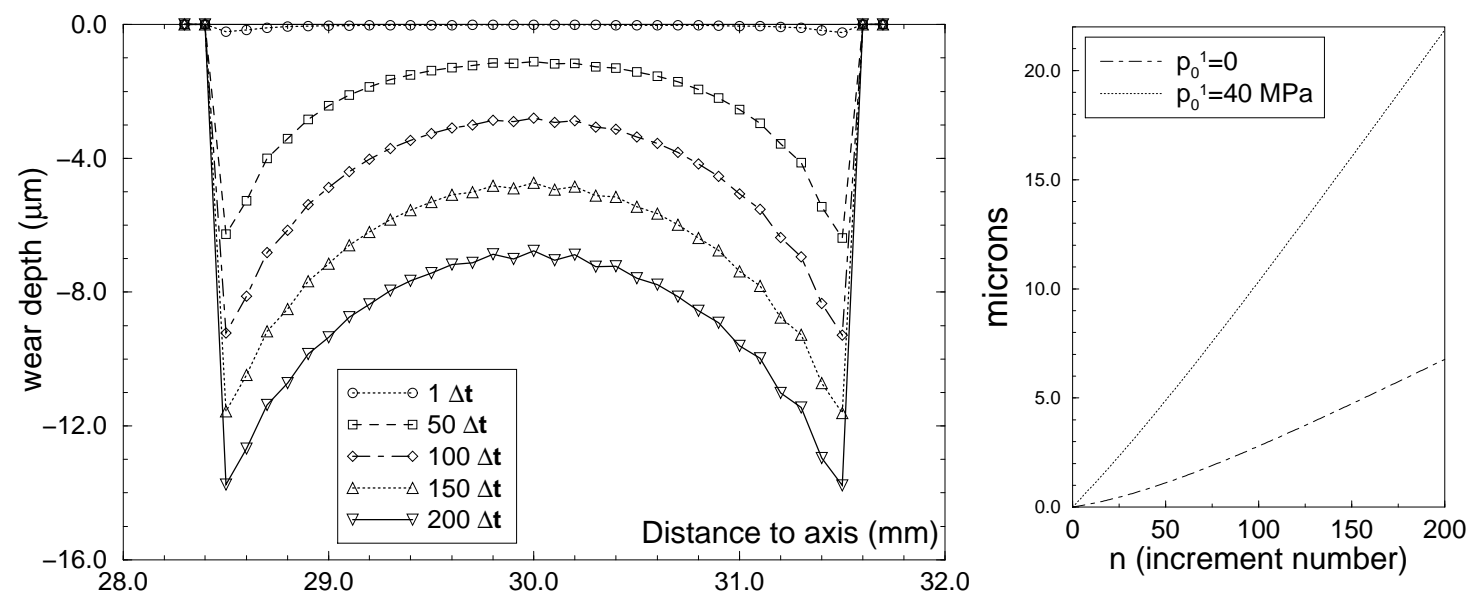

Figure 2: Numerical example of wear simulation: computed evolution of the contact surface (on ring 1) due to wear, with $p_{1}^{0}=40 \mathrm{MPa}$ (left); comparison of computed evolutions of the penetration depth for $p_{1}^{0}=0$ or $40 \mathrm{MPa}$ (right).

Exemple numérique de simulation d'usure: évolution calculée (sur l'anneau 1) de la surface de contact due à l'usure, avec $p_{1}^{0}=40 \mathrm{MPa}$ (gauche); comparaison des évolutions calculées de la profondeur de pénétration pour $p_{1}^{0}=0$ or $40 \mathrm{MPa}$ (droite).

antagonist materials is assumed and the nonlinear components of the problem reside entirely on the contact surface. Likewise, the wear law (4) was used as a representative example, but more general wear laws expressing $f_{w}(\boldsymbol{x}, t)$ in terms of the current (and possibly past) mechanical state at time $\tau \leq t$, and possibly of non-local form, could be considered with only minor modifications to the overall present solution scheme. Finally, the present strategy can be generalized to cases where e.g. ring 1 is coated with a thin layer with elastic properties differing from those of the substrate, along the lines of ref. [3] (which investigates a BEM formulation for coated half-spaces); in that case a domain integral over the coating, and involving the contrast of elastic moduli, appears in the integral equation (5).

\section{References}

[1] Bonnet, M. Regularized BIE formulations for first- and second-order shape sensitivity of elastic fields. Computers and Structures, 56, 799-811 (1995).

[2] Bonnet, M. Boundary integral equations methods for Solids and Fluids. John Wiley and sons (1999).

[3] Dong, C., Bonnet, M. An integral formulation for steady-state elastoplastic rolling/sliding contact over a coated half-plane. In A. Carosio, et al. (eds.), Fifth US National Congress on Computational Mechanics, p. 74 (1999).

[4] Lederer, G. Modélisation tribo-mécanique du frottement en milieu agressif. Ph.D. thesis, Ecole Polytechnique (1998).

[5] Serre, I. Contribution à l'étude des phénomènes d'usure par frottement en milieu marin. Ph.D. thesis, Ecole Polytechnique (2000).

[6] Walter, A., Plitz, W. The ring on disc method : clinical significance of a wear-screening test of biomaterials for hip joint alloplasty. In S.M. Perren, E. Schneider (eds.), Current Interdisciplinary Research, pp. 129-134. Martinus Nijoff, Dordrecht (1985). 